\title{
Gritos dan en el real... \\ Figuras de mujer en la propaganda política y social de la Edad Media hispana
}

\section{Gritos dan en el real... Using women for political propaganda in the Spanish Middle Ages}

\author{
MaRía Jesús Fuente \\ Universidad CARlos III de Madrid
}

\begin{abstract}
RESUMEN
La propaganda política durante la Edad Media utilizó en ocasiones a las mujeres como arma arrojadiza entre facciones, dándose así la paradoja de que las figuras femeninas, excluidas del espacio político, eran claves en épocas de conflicto. Para demostrarlo se analizan tres momentos cruciales en la monarquía castellana, en los que se producen enfrentamientos entre hermanos por cuestiones sucesorias, $y$ en los que se utiliza a las mujeres de la familia como medio para desprestigiar al contrario. En el último tercio del siglo XI, la rivalidad entre Sancho II y Alfonso VI, tuvo en medio a su hermana Urraca de Zamora; a mediados del siglo XIV, el enfrentamiento entre Pedro I y Enrique II, utilizó a varias mujeres de la familia como medio de propaganda; en la segunda mitad del siglo XV, la pugna entre Enrique IV e Isabel de Castilla, envolvió también a las mujeres de la familia.
\end{abstract}

\section{PALABRAS CLAVE}

propaganda política, mujeres medievales, pugnas sucesorias.

\section{ABSTRACT}

During the Middle Ages Spanish monarchs and nobles developed a form of political propaganda in which women were used as weapons against their political rivals. The result was that female figures, excluded from the political arena, took a great role in problematic periods. To illustrate this point, I analyze three cases from crucial times of the Kingdom of Castile, when in the fights for the throne between siblings, women of the immediate family were involved. One, which took place in the second half of the XIth century, involved the rivalry between Sancho the IInd and Alfonso the VIth. Another which centered on the rivalry between Pedro the Irst and Enrique the IInd, occurred in the middle of the XIVth century. And the third, which took place in the second half of the XVth century, pitted Enrique the IVth and Isabel of Castile.

\section{KEY WORDS}

political propaganda, medieval women, inheritance fights. 
En el otoño del año 1507, el rey Fernando el Católico llamaba a la corte, en aquel tiempo en Burgos, a una terciaria dominica llamada María de Santo Domingo. Quería conocerla y escucharla. Nacida en el seno de una pobre familia campesina de una localidad cercana a Salamanca, María no sabía leer ni escribir, pero su fama se había ido extendiendo por todo el reino de Castilla; los hombres más importantes del reino, el propio rey, el cardenal Cisneros y el gran duque de Alba, querían oírla. Era insólito que esos grandes personajes estuvieran interesados en prestar atención a las palabras de una monja iletrada. ¿Qué movía a esos próceres a prestar oídos a esta joven mujer: fervor religioso o alguna otra intención? ¿Cabría sospechar que podía servirles para alguno de sus fines políticos? ¿En qué medida las mujeres de aquel tiempo eran utilizadas en la «propaganda política» de los varones que las rodeaban?

La respuesta a estas preguntas requiere plantear una cuestión previa: ¿hasta qué punto se puede hablar de propaganda en general y de propaganda política en particular durante la Edad Media?. Como proceso comunicativo con finalidad de persuadir al público y lograr la modificación de su conducta, la propaganda política «pretende la perpetuación o el cambio en las estructuras de poder. La intencionalidad de toda propaganda puede resumirse en el siguiente objetivo: conquistar o mantener el poder. Si éste no se posee, se aspira a lograrlo, enfrentándose a quien lo detente. Si el emisor ya posee el poder, su propaganda se encaminará a conseguir la afirmación y perpetuación en el mismo"'1. Su expansión se realiza mediante procesos de comunicación que «difunden los valores, las normas y las creencias que forman las ideologías políticas»².

Aunque en la actualidad se mezclan propaganda y publicidad política, y estas fórmulas están muy alejadas de la difusión de ideas en la etapa medieval, se podría afirmar que en la Edad Media no faltó el hecho propagandístico. En efecto, no todos, pero sí la mayoría de los elementos de las definiciones citadas, pueden aplicarse a la Edad Media, en especial lo referente a la perpetuación o al cambio de manos del poder. Esa propaganda se hacía por los reyes con ánimo de influir en sus súbditos aunque no dependiera de éstos la permanencia del monarca en el trono.

Para entender la propaganda política en tiempos medievales habría que preguntarse: ¿de quién salía y para quién se hacía la propaganda? ¿Qué valores se difundían? ¿Qué medios o instrumentos se utilizaban para la difusión?

La teoría y la propaganda políticas, como producciones culturales y prácticas sociales implicadas en el proceso político ${ }^{3}$, estuvieron durante el Medievo en rela-

\footnotetext{
1. «Mecanismos básicos de la propaganda de guerra en los medios informativos. El ejemplo de Kosovo». María José GARCÍA ORTA, Ámbitos, 7-8, 2002; ideas tomadas de María Victoria REYZÁBAL, Propaganda y manipulación. Madrid, Acento Editorial, 1999, p. 40.

2. José Manuel NIETO SORIA, «Apología y propaganda de la realeza en los cancioneros castellanos del siglo XV», En la España Medieval, 11, 1988, 196.

3. Jacques VERGER, «Théorie politique et propagande politique», en Le forme de la propaganda politica nel due e nel trecento, ed. P. Cammarosano, Roma, École Française de Rome, 1994, p. 30.
} 
ción con la defensa de la monarquía y de los valores del rey. Sus cronistas o los hombres de saber que le rodeaban eran los encargados de difundir la imagen del monarca, divulgada también en ceremonias diversas. Los cancioneros, los romances, o los sermones fueron vehículos para llegar a súbditos más o menos cultos. Desde la obra de Tomás de Aquino o de Alfonso X se percibe la necesidad de hacer llegar al pueblo la naturaleza del poder: lo positivo o lo reprobable de un monarca.

Este tema ha interesado a algunos medievalistas que han dedicado su atención principalmente a la etapa de ascenso al poder de Isabel de Castilla ${ }^{4}$. En ese tiempo de debate entre la legitimidad de dos mujeres, la princesa Isabel y su sobrina Juana, la propaganda tuvo un papel primordial. Aunque en menor medida, la propaganda tendría gran importancia también en otras etapas de la Edad Media. Se trata de un tema que requiere de mayor atención en general, en concreto la parte que se relaciona con la aparición de figuras femeninas en momentos de propaganda intensa. En efecto, no se ha estudiado convenientemente el papel de las mujeres medievales en la divulgación de valores de su tiempo, aunque sí se ha percibido su importancia al apreciar el culto a María como un gran hogar de propaganda ${ }^{5}$.

El papel de las figuras femeninas en relación con la propaganda política se ha puesto de manifiesto en el interesante estudio de Anne J. Cruz sobre las mujeres del entorno de Pedro I el $\mathrm{cruel}^{6}$, en el que esta autora apunta varios aspectos a tener en cuenta en el análisis de la relación entre mujeres y propaganda. En primer lugar el de los medios formales de difusión, los romances, que recreaban y delimitaban conductas de género al recordar «a las audiencias, al tiempo que se les in-

\footnotetext{
4. J. M. NIETO SORIA, «Apología y propaganda de la realeza...»185-221; «La ideología política bajomedieval en la historiografía española», Hispania, 175, 1990, 667-681,..»Les clercs du roi et les origines de l'Etat Moderne en Castille. Propagande et légitimation (XIIle-XVe siècles)», Journal of Medieval History, 18, 1992, 297-318 ; Las ceremonias del poder en la España Medieval. Propaganda y legitimación de la realeza Trastamara en Castilla, Madrid, Nerea, 1993; «Propaganda política y poder real en la Castilla Trastamara: una perspectiva de análisis», Anuario de Estudios medievales, 25/2, 1995; «Propaganda and legitimation in Castile: Religion and Church 1250-1500, en The Origins of the Modern State in Europe:Iconography, Propaganda and legitimation, ed. Allan Ellenius, Oxford, Oxford University Press, 1998, 105-119; Orígenes de la monarquía hispánica: propaganda y legitimación (ca. 1400-1520), Madrid, Dykinson, 1999; «Ideología y propaganda política en la Europa medieval: los proyectos integradores», Mitos tópicos y realidades del poder en Europa y América, Ed. E. García Fernández, Vitoria, Universidad del País Vasco, 2001. Ana Isabel CARRASCO MANCHADO, «Aproximación al problema de la conciencia propagandística en algunos escritores políticos del siglo XV», En la España Medieval, 21 (1998), 229269; «Discurso político y propaganda en la corte de los Reyes católicos: resultados de una primera investigación (1474-1482)», En la España Medieval, 25, 2002, 299-379; Isabel I de Castilla y la sombra de la ilegitimidad. Propaganda y representación en el conflicto sucesorio (1474-1482), Madrid, Sílex, 2006. Luis Suárez, tiene un libro con un título muy expresivo del papel de la propaganda en este tiempo: Enrique IV. La difamación como arma política, Barcelona, Ariel, 2001. Shima Ohara, La propaganda política en torno al conflicto sucesorio de Enrique IV (1457-1474), Valladolid, 2004.

5. J. Le GOFF, «Conclusions», Le forme de la propaganda politica nel due e nel trecento, p. 524.

6. A. J. CRUZ, «The Female Figure as Political Propaganda in the «Pedro el Cruel» Romancero», Spanish Women in the Golden Age. Images and Realities, M. S. Sánchez y A. Saint-Saëns (eds.), Westport, Greenwood Press, 1996, pp. 69-89.
} 
formaba y entretenía, de los papeles sociales y morales aceptables para las mujeres dentro del sistema patriarcal de poder ${ }^{7}$. En segundo lugar, Cruz analiza detenidamente los temas de fondo, es decir, las conductas femeninas a través de los ejemplos de tres mujeres en relación con Pedro I. Finalmente expone de forma breve pero muy sugerente algunos de los puntos a tener en cuenta al evaluar el papel de las mujeres en la política del grupo familiar al que pertenecen: su utilización para justificar acontecimientos políticos, para dar una imagen modélica de las mujeres o para expresar nuevas realidades sociales.

Este estudio de Anne J. Cruz abre un campo de investigación interesante, pues hay que suponer que otras mujeres tendrían un papel significativo en la propaganda del tiempo que las tocó vivir. En la búsqueda del papel femenino en la propaganda política aparecen algunos momentos en los que de manera especial las mujeres participaron o fueron utilizadas en problemas de la monarquía o de la familia real a la que pertenecían o estaban cercanas. En dos momentos cruciales del reino de Castilla, además del reinado de Pedro I, las mujeres tuvieron especial protagonismo: en el último tercio del siglo XI, cuando Doña Urraca, la señora de Zamora, tuvo un papel significativo en el conflicto que enfrentó a sus hermanos Sancho II y Alfonso VI, y en la segunda mitad del siglo XV, una pugna entre hermanastros, Enrique IV e Isabel I, introdujo a las mujeres, Juana la Beltraneja, Juana de Portugal y la propia Isabel de Castilla, en la propaganda política de aquel tiempo.

En este artículo vamos a analizar en qué medida o de qué manera las mujeres fueron parte de la propaganda, como objeto o sujeto, o como simple instrumento del discurso político de su tiempo, estudiando su papel en esos dos momentos políticos, y en el tiempo de enfrentamiento entre otros dos hermanastros, Pedro I el cruel y Enrique II de Trastamara, que llevó a escena a varias mujeres de la familia: Blanca de Borbón, María de Padilla, María de Portugal y Leonor de Guzmán. En el estudio de cada uno de esos tiempos se plantearán las cuestiones arriba citadas acerca de los medios formales de presentar a esas mujeres, su utilización en aspectos concretos de la política y la sociedad de su tiempo, y la finalidad perseguida o conseguida con esa utilización. Ello permitirá vislumbrar si hubo unos modelos propagandísticos comunes, y si en todos los casos se llegó a conseguir la doble finalidad de comunicación de valores políticos y sociales.

\section{DOÑA URRACA DE ZAMORA EN EL CONFLICTO ENTRE SANCHO II Y ALFONSO VI}

Una de las figuras femeninas más conocidas de la Edad Media hispana es doña Urraca de Zamora (1033-1101). Debe la fama a su protagonismo en muchos 69.

7. A. J. CRUZ, «The Female Figure as Political Propaganda in the «Pedro el Cruel» Romancero», p. 
de los romances del cerco de Zamora, que se hacían eco de lo que las crónicas habían recogido acerca de ella. Los cronistas se encargaron de ir escribiendo una historia a la medida de las necesidades del reino y de las ideas que los poderosos querían difundir ${ }^{8}$, y los juglares la propagaban a nivel popular mediante romances.

Muchos son los romances del cerco de Zamora, y muchos en los que aparece doña Urraca ${ }^{9}$. Si se tiene en cuenta que las mujeres suelen aparecer en los documentos medievales por su afiliación a los hombres, y que eran varones quienes escribían y, por tanto, decidían qué figuras de mujer incluían en sus escritos ${ }^{10}$, llama especialmente la atención que doña Urraca haya llegado a ser uno de los personajes más divulgados de la Edad Media hispana. Su presentación en crónicas y romances permite reconstruir la historia de doña Urraca durante un tiempo limitado, desde la muerte de su padre, Fernando I, en 1065, hasta la de su hermano primogénito, Sancho II, en 1072. Su primera aparición es ante el lecho de muerte de su padre, donde se presenta a doña Urraca quejándose del testamento de su padre:

Mandastes las vuestras tierras / a quien se vos antojara:

diste a don Sancho a Castilla, / Castilla la bien nombrada,

a don Alfonso a León / con Asturias y Sanabria,

a don García a Galicia / con Portugal la preciada

Doña Urraca se queja de la injusticia de no recibir nada en ese reparto

¡y a mí, porque soy mujer, / dejáisme desheredada!

y amenaza con:

Irme he yo de tierra en tierra / como una mujer errada; mi lindo cuerpo daría / a quien bien se me antojara, a los moros por dinero / y a los cristianos de gracia; de lo que ganar pudiere, / haré bien por vuestra alma.

Las amenazas de Urraca conmueven al rey, que pare evitar que llegara a ser una mujer descarriada la concede un territorio:

Allá en tierra leonesa / un rincón se me olvidaba, Zamora tiene por nombre, / Zamora la bien cercada, de un lado la cerca el Duero, / del otro peña tajada. ¡Quien vos la quitare, hija, / la mi maldición le caiga! Todos dicen: «Amen, amen», / sino don Sancho que calla.

\footnotetext{
8. S. MARTÍNEZ, «Tres leyendas heroicas de la Najerense y sus relaciones con la épica castellana», Anuario de Letras, 9 (1971), 115-177. G. MARTIN, «Dans l'atelier des faussaires. Luc de Túy, Rodrigue de Tolède, Alphonse X, Sancho IV: trois examples de manipulations historiques (León-Castille, XIII siècle ", Cahiers de lingüistique et de civilisation hispanique médiévale, 24 (2001), 279-302.

9. E. FERNÁNDEZ PRIETO, Romancero de Zamora, Zamora, 1973.

10. Lisa M. BITEL, Women in Early Medieval Europe. 400-1100, Cambridge Univ. Press, 2002 p. 1.
} 
Hija de los reyes Fernando I y Sancha, Urraca participó activamente en el conflicto que enfrentó a sus dos hermanos, Sancho II y Alfonso VI. Un romance registra su petición a Sancho de dejar libre a su hermano Alfonso, a quien Sancho había apresado, pero su mediación no tiene éxito, pues Sancho le contesta:

-Mal hayas tu, hermana,/ Y quien tal te aconsejó,

Que mañana, de mañana,/ Muerto te lo diera yo.

La intervención de doña Urraca en el conflicto entre los hermanos, en concreto la bien conocida historia del foco rebelde de Zamora y la muerte de Sancho a manos de Vellido Dolfos, ha sugerido la pregunta de su posible responsabilidad en la muerte de Sancho II. Pero son también los romances los que se encargan de exculparla:

Sobre el muro de Zamora; vide un caballero erguido; al real de los castellanos da con grande grito:

- iGuarte, guarte, rey don Sancho, no digas que no te aviso, que del cerco de Zamora un traidor había salido; Vellido Dolfos se llama, hijo de Dolfos Vellido, si gran traidor fue su padre, mayor traidor es el hijo; cuatro traiciones ha hecho, y con ésta serán cinco! Si te engaña, rey don Sancho, no digas que no te aviso.

Gritos dan en el real: ¡A don Sancho han mal herido! ¡Muerto le ha Vellido Dolfos; gran traición ha cometido!

El protagonismo de Urraca en tantos romances plantea la pregunta: ¿Por qué esta infanta aparece con tanta frecuencia en los romances y en las crónicas, es decir, en los medios de propaganda de la época? La recurrencia al tema de la muerte de Sancho en Zamora, de donde era señora y donde se encontraba su hermana Urraca, hace pensar en algún interés especial, o en algún mensaje subliminal más allá de la simple transmisión de una historia. Hay que preguntarse, pues, por las posibles ideas que se perseguía propagar. En primer lugar podría tratarse de divulgar la idea de la herencia legítima de Urraca, que recibió Zamora al repartir su padre el reino entre sus hijos; a ella le concedió esta ciudad, en tanto que a sus hermanos les entregaba los reinos de Castilla, León y Galicia. En segundo lugar podría pretenderse difundir la creencia de que Sancho quiso saltarse la voluntad de su padre al arrebatar los territorios a sus hermanos. Por último, se insiste de manera tenaz en la idea de que Urraca no intervino en la muerte de Sancho, sino que fue el traidor de Vellido Dolfos, quien de forma individual decidió acabar con la vida del rey; así se salvaba el honor de Urraca y el de Zamora, sobre quienes recaía la sospecha de traición.

Estas tres posibles líneas de interés propagandístico en cierta manera se entrecruzan, y pueden servir para la difusión de aspectos de carácter político que no aparecen a primera vista. Se estaba empezando a plantear el problema de la confrontación entre dos maneras de entender la monarquía: la monarquía patri- 
monial o feudal, propicia a la división de los reinos, y la monarquía unitaria, garante de la integridad del reino al pasar de padres a hijos. Junto a esa confrontación se encontraba la defensa de la necesidad de unión de los reinos de León y Castilla, con su larga historia de uniones y desuniones.

Sancho II había desobedecido la voluntad de su padre al tratar de conquistar todos los territorios de sus hermanos. Tras arrebatar los territorios de García y Alfonso, le interesaba la ciudad de su hermana Urraca, pues, según la Crónica General, Sancho había dicho «Teniendo yo a Zamora, dijo a los de su séquito, me podría llamar señor de España». Sancho, como castellano, iniciaba así la andadura de aglutinar los territorios que formarían España. Era el primer monarca que defendía el centralismo castellano y la unión de España. Los defensores de la idea contraria, sus hermanos Alfonso y Urraca, se habían aprovechado de los acontecimientos y habían conseguido quedarse con todos los territorios unificados. Sin embargo, esa unidad se había conseguido mediante la traición. Había que demostrar, pues, que no había habido tal traición, y había que dejar limpio el nombre de doña Urraca, de Zamora y del rey Alfonso VI.

La propaganda difundida en los romances perseguía dar la vuelta a los sucesos de Zamora y demostrar que no se había atentado contra los valores centralistas representados por el rey de Castilla. Había sido un simple problema de familia: un hijo díscolo y desobediente recibió el castigo merecido aunque no fuera intencionado; una hija que defendía los valores representados por su padre y apoyaba al hermano desvalido. Urraca, en consecuencia, había actuado como la típica hermana mayor que defiende a la familia:

Lloró la hermana, maguer que enemiga,

Al rey don Sancho, e con grand sentido

Procedió presto contra el mal Bellido

Servando en acto la fraternal liga ${ }^{11}$

El protagonismo de Urraca probablemente trataba de silenciar el papel de su hermano Alfonso VI. Es la figura femenina la que se divulga en los romances y, mientras que otros personajes masculinos aparecen en el drama de Zamora (Arias Gonzalo o Rodrigo Díaz de Vivar), el rey Alfonso apenas si asoma, se le menciona poco y, así, sale intacto de esa historia. Serían estos romances un buen ejemplo de este género literario que ha dado una imagen de las mujeres «metaforizándolas en categorías abstractas que reflejan y sirven los intereses masculinos» ${ }^{12}$.

La facción castellana, partidaria de Sancho II, no pudo hacer una propaganda tan intensa contra Urraca y Alfonso. En un principio acusaron a la infanta de ser una mala mujer que asesinó a su hermano, pero la mayor parte de los romances se escribieron siglos más tarde, cuando se había extinguido cualquier atisbo de rei-

11. Soneto del Marqués de Santillana. E. FERNÁNDEZ-PRIETO, Romancero de Zamora. Romance 48, p. 94.

12. A. J. CRUZ, «The Female Figure as Political Propaganda...», p. 70. 
vindicación de la figura del monarca muerto. Juzgaban a Urraca responsable del asesinato de Sancho II, y a Alfonso beneficiario de la sedición de Urraca. El epitafio de Sancho II, compuesto por un monje de Oña, dice: "Su hermana, mujer de ánimo cruel, le despojó de la vida, conculcando todo derecho, ni siquiera lloró al hermano asesinado. Este rey fue muerto por el consejo traicionero de su hermana Urraca». La desconfianza de los castellanos ante Alfonso VI, se expone en el romance de la jura de Santa Gadea, aunque fuera una ceremonia que probablemente nunca se realizó ${ }^{13}$.

La propaganda contra Urraca difundió también la idea de que la infanta había prometido favores sexuales a Vellido Dolfos en pago al riesgo que corría al ir a matar al rey:

Desque le tuviera muerto, metióse por un postigo, por las calle de Zamora va dando voces y gritos:

- ¡Tiempo era, doña Urraca, de cumplir lo prometido!

La propaganda negativa contra Urraca utilizó el tema de una posible relación incestuosa entre Urraca y su hermano Alfonso. Aunque es poco probable, algunas crónicas árabes se encargaron de difundirlo, al tiempo que era útil para los enemigos de la infanta y su hermano el rey. Se encuentra aquí un aspecto negativo de las mujeres, utilizado en la propaganda política para desprestigiarla no solo a ella, sino especialmente a su hermano, al que habría que culparle del pecado de incesto.

Pero aparte de la propaganda política, Urraca servía para hacer propaganda social, en la medida que su figura se utiliza para difundir un modelo de mujer. De sobresalir por su «comportamiento y belleza» ${ }^{14}$, de ser «astuta y prudente», así como «mujer juiciosa y entregada a obras piadosas» la califica Jiménez de Rada ${ }^{15}$. «Duenna muy entenduda et sesuda» y con «bondad et seso» la describe la Primera Crónica General16. Le añade el calificativo de prudente el Chronicon Compostellanum ${ }^{17}$.

El interés de difundir la historia de Doña Urraca se hace más complicado si se tiene en cuenta que su protagonismo se hace especialmente interesante en los romances, escritos siglos después de su vida. Fue en momentos conflictivos de la historia de la corona de Castilla, en etapas de debate sobre legitimidad, cuando sale a relucir la figura de esta infanta. Castilla y León, unidos o desunidos en distintos momentos de su historia, padecieron los enfrentamientos entre quienes

13. María Jesús FUENTE, “Ceremonias reales y ceremonias virtuales en la vida de El Cid», Tiempo y Tierra, 13, 2002, 39-53.

14. R. JIMÉNEZ DE RADA, Historia de los Hechos de España, libro sexto, capítulo VIIII, (ed. J. Fernández Valverde), Madrid, Alianza Editorial, 1989, p. 230.

15. R. JIMÉNEZ DE RADA, Historia de los Hechos de España, libro sexto, capítulo XX, p. 244.

${ }^{16}$. Primera Crónica General, capítulo XIX, en Carola REIG, El cantar de Sancho Il y cerco de Zamora, Madrid, CSIC, 1947.

17. Edición de A. HUICl, Valencia, 1913, I, p. 85. 
respaldaban la idea de caminar unidos o separados. La división de los reinos al morir Alfonso VII (1126-1157), su unión por Fernando III (1217-1252), tras los debates acerca de su legitimidad, los enfrentamientos al final del reinado de Alfonso $X$, la dudosa legitimidad de Enrique II de Trastamara (1369-1379), y la también dudosa legitimidad de Isabel de Castilla, es decir en circunstancias de enfrentamiento político por cuestiones de legitimidad, «consustanciales a la evolución de la monarquía castellano-leonesa»18, pudo interesar difundir algunas de las ideas citadas, utilizando la figura de doña Urraca como defensora de la unidad del reino por encima de cualquier eventualidad. Se seguía así la tendencia medieval de utilizar un personaje con fines propagandísticos, sin ningún escrúpulo de si se era fiel a la verdad o no.

\section{LAS MUJERES EN EL CONFLICTO ENTRE PEDRO I Y ENRIQUE II}

El conflicto que enfrentó a estos dos hermanastros, adalides de dos líneas políticas enfrentadas, se remonta al reinado de su padre, el rey Alfonso XI, hostilizado por la nobleza por su política de afianzamiento del poder regio. El descontento de los nobles, que vislumbraban su descenso a posiciones menos poderosas, tuvo efectos graves tras la muerte del rey. Pedro I, su único hijo legítimo, le sucedió en el trono y reprodujo la conducta de su padre, tanto a nivel político como personal. En lo político continuó la obra de afianzar el autoritarismo regio, y en lo personal siguió el modelo paterno de abandonar a su esposa legítima para vivir con su amante y madre de sus hijos.

Las mujeres en relación con padre e hijo, se las conoce a través de romances y baladas, en las que se hace un esfuerzo por ganar el apoyo popular para la causa de los Trastamara. Para Anne J. Cruz, los romances muestran figuras femeninas reprimidas simbólicamente ${ }^{19}$, en contraste con la realidad de las mujeres de los grupos elevados, influyentes y poderosas, aceptando la idea de que en aquella época las mujeres tenían un poder o una influencia remarcables ${ }^{20}$; sin embargo, no es fácil suscribir esa idea, pues las figuras femeninas del entorno de Pedro I no tuvieron tal poder, como no lo tuvieron las mujeres en general, salvo excepciones ${ }^{21}$. Un breve examen de las mujeres de ese entorno lleva a dudar de su influencia o poder ${ }^{22}$.

18. J. M. NIETO SORIA (director), La monarquía como conflicto en la corona castellano-leonesa (c. 1230-1504), Sílex, Madrid, 2006, p. 68.

19. A. J. CRUZ, «The Female Figure as Political Propaganda...», p. 71.

20. Defienden ese poder de las mujeres en la Edad Media hispana algunas autoras, como Heath DILLARD, Daughters of the Reconquest: Women in Castilian Town Society, 1100-1300, Cambridge, Cambridge University Press, 1984, y Mercedes VAQUERO, La mujer en la épica castellano-leonesa en su contexto histórico, México, UNAM, 2005.

${ }^{21}$. María J. Fuente, « ¿Reina la reina? Mujeres en la cúspide del poder en los reinos hispánicos de la edad media (siglos VI-XIII)», Espacio, Tiempo y Forma, Serie III, Historia Medieval, 16, 2003, 53-71.

22. Helen M. JEWELL, Women in Dark Age and Early Medieval Europe c. 500-1200, Houndmills y New York, Palgrave McMillan, 2007; Women in Late Medieval and Reformation Europe 1200-1550, Houndmills y New York, Palgrave McMillan, 2007. 
En primer lugar, llama la atención la diferencia entre las dos mujeres en relación con Alfonso XI. María de Portugal, como reina legítima durante el reinado de su esposo, estuvo anulada o fue manejada en ese papel útil de mediadora que siempre tuvieron las reinas; al morir su esposo, convertida en reina madre, su papel inicial fue vengativo, para castigar a la familia paralela que había mantenido su esposo; pronto su hijo Pedro no la dejó actuar o hizo caso omiso de sus consejos, hasta el punto de que ella se alineó con los enemigos de su hijo, lo que le ha valido el título de «virago» que le han aplicado algunos historiadores ${ }^{23}$. Así pues, solo hubiera podido ejercer influencia o poder durante el reinado de su hijo, pero éste no le permitió ejercerlo. Leonor de Guzmán, la amante de Alfonso XI y madre de sus diez hijos ilegítimos, llegó a ser una poderosa gran señora feudal a través del patrimonio que pudo reunir con los grandes regalos que le hacía el rey al nacer cada uno de sus hijos; muy influyente mientras vivió Alfonso XI, fue una de las primeras víctimas de la venganza de María de Portugal.

No es muy diferente la situación de las mujeres en relación con Pedro I. Blanca de Borbón, la esposa despreciada por el rey, sin poder e influencia alguna, fue víctima de la situación. María de Padilla, el amor del rey Pedro, llevaba camino de convertirse en otra Leonor de Guzmán, de no haber muerto a una edad temprana. Juana de Castro, un capricho momentáneo de ese mismo monarca, que se casó con ella y la abandonó de inmediato, como había hecho con su otra esposa legítima. Aunque Juana pertenecía a una de las familias de mayor linaje castellano, el rey no tuvo inconveniente en abandonarla también al día siguiente de la boda. Una noble familia despechada y un asunto más para echar leña al fuego de una nobleza descontenta con el monarca.

Mientras no se las utilizó para la propaganda política, probablemente tuvieron más influencia las mujeres amadas por el rey, aunque fueran concubinas, pues posiblemente los súbditos, en concreto los nobles, no se atrevían a ir en contra de los deseos del monarca o querían complacerle.

De una forma $u$ otra todas estas mujeres se resintieron de la conducta de los reyes, y su vida personal se mezcló con la política del reino, tal como se refleja en los romances en los que aparecen. La mayor parte de ellas, María de Portugal, Leonor de Guzmán, Blanca de Borbón y María de Padilla, salen en los romances de una forma u otra, en algunos especialmente como protagonistas de la propaganda.

Tanto la reina, María de Portugal, como la amante, Leonor de Guzmán, son objeto de elogios en el Poema de Alfonso Onceno.

A la reina se le ensalzan sus virtudes:

e casó con la mejor / Reina en el mundo nacida: Señora non saben tal, / honesta, bien pare(s)ciente, (qu)e nasció en Portogal,/ en el cabo del Poniente ${ }^{24}$

23. A. J. Cruz, «The Female Figure as Political Propaganda...», p. 71.

24. Estrofas 405-406 del Poema de Alfonso Onceno, ed. Juan VICTORIO, Madrid, Cátedra, 1991, p. 121. 
al tiempo que aparece en ese Poema cumpliendo con sus obligaciones, especialmente con el cometido de mediar entre su esposo el rey y su padre, el rey de Portugal ${ }^{25}$.

Leonor de Guzmán recibe una lista de elogios aún mayor:

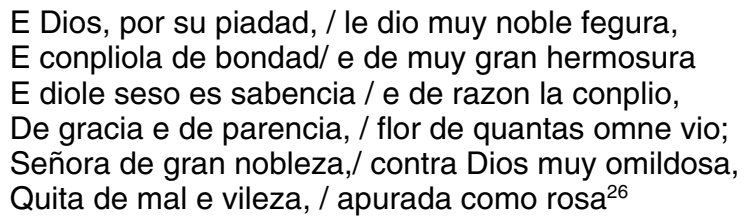

Si no hay diferencia a la hora de ensalzar a ambas mujeres en relación con el rey Alfonso XI, el tratamiento sería radicalmente distinto con las mujeres vinculadas a Pedro I. Al abandonar Pedro a Blanca de Borbón nada más casarse, la reacción desde distintos frentes no se hizo esperar. Su madre, María de Portugal, y su tía Leonor, la reina viuda de Aragón, se presentaron a suplicarle que no abandonara a la joven desposada ${ }^{27}$. El propio Papa envió una bula con recomendaciones a los recién casados, aunque la fecha hace dudar de su veracidad y plantea el problema de cómo se enteró el Papa de que el rey había abandonado a Blanca y de quién le hizo llegar la noticia ${ }^{28}$. El clero estaba de parte de la reina, o al menos eso parece mostrar su refugio en la catedral de Toledo, a invitación del propio arzobispo. La protección del espacio sagrado fue vista con buenos ojos por otros miembros del alto clero, movidos por el apoyo del Papa a la reina Blanca. Ésta, por primera y quizás última vez, mostró una postura rebelde, y consiguió el apoyo de la ciudad de Toledo que se levantó contra el rey, en el verano de 1354. Otras ciudades secundaron a Toledo y pidieron al monarca que volviera con la reina Blanca y abandonara a María de Padilla. El Romance del rey Don Pedro el Cruel se hace eco de esas peticiones:

Quieres mal a doña Blanca, / A Dios ensañas por ello;

Que si tornas a quererla / Darte ha Dios un heredero,

Y sino, por cierto sepas / Te vendrá desmán por ello. ${ }^{29}$

Los nobles también instaron al rey a cumplir con sus obligaciones de recién casado. En las «vistas» de Tejadillo, donde los nobles se presentaron con el cadáver de Alburquerque, responsable de la boda con Blanca de Borbón ${ }^{30}$, los nobles pidieron al rey que «Doña Blanca vuestra muger sea con vos honrada, como lo fueron las otras Reynas de Castilla».

25. Estrofas 1013-1033, Poema de Alfonso Onceno, pp. 226-229.

26. Estrofas 383-389, Poema de Alfonso Onceno, pp. 115-116

27. Crónica de Pedro I, año 1353. Edición de la BAE, p. 433.

${ }^{28}$. La fecha de esta bula, 1 de mayo de 1353, plantea cuestiones interesantes, pues la fecha de la boda, según algunos autores, fue el 3 de junio de 1353. ¿Fue la boda antes? ¿Cómo se enteró el Papa de las desavenencias matrimoniales?

29. Poesía tradicional lírica y romancero, ed. A. BERLANGA, Madrid, Alce, 1978, p. 144.

30. Alburquerque había hecho prometer a los suyos que no enterrarían su cadáver hasta que el rey no accediera a volver con la reina. 
No le habían pedido eso a su padre cuando convivía con Leonor de Guzmán, y les tenía abandonados a él y a su madre. Pero Pedro jugaba con desventaja respecto a su padre, tenía en contra a un grupo muy numeroso de la nobleza, como consecuencia de sus actuaciones políticas, en la línea del afianzamiento del poder regio; unos le volvieron la espalda, otros emigraron al cercano reino de Aragón, y no faltaron algunos que fueron más lejos a participar en el conflicto que por aquellos días enfrentaba a Francia e Inglaterra, la Guerra de los Cien Años.

La actitud de la nobleza respondía a la postura de Pedro I, que había tomado medidas radicalmente opuestas a lo que se le había pedido y, en un gesto de volver la espalda a los nobles, había depositado su confianza en el círculo de parientes de su amada María de Padilla. Los nobles no pararon en su empeño de conseguir el cambio del rumbo iniciado por Pedro, y pidieron entrevistarse con él en Toro. Allí se presentó un grupo numerosos de nobles acompañado de las mujeres de la familia: la madre María de Portugal, la esposa Blanca de Borbón, y la tía Leonor de Aragón. Era una auténtica encerrona para Pedro que se vengaría por ello, empezando por las mujeres de la familia. La reina María recibió el perdón, pero las otras dos, Blanca y Leonor, antes o después, pagarían la infidelidad al monarca. Pedro culpó a Blanca de la sublevación de Toledo y esa fue la excusa para encarcelarla, mantenerla incomunicada y posteriormente ejecutarla.

Los nobles, empeñados al principio en obligar al rey a cumplir con sus obligaciones de recién casado, utilizaron luego a la reina despreciada como una buena excusa para enfrentarse al rey. Las uniones de los monarcas eran en buena medida inseparables de los asuntos políticos, de ahí que las esposas $u$ otras mujeres de su entorno aparezcan en muchas ocasiones como parte de la propaganda de uno de los bandos. Ese es el caso de la reina Blanca, instrumento de propaganda política utilizada por los enemigos del rey, que le acusaban, junto a su amante, de la muerte de la reina, dibujada como joven desvalida de buen corazón:

Doña María de Padilla, no os mostredes triste, no: si me descasé dos veces hícelo por vuestro amor, Y por hacer menosprecio de doña Blanca de Borbón.

...

Llamara Alonso Ortíz, que es un honrado varón, para que fuese a Medina a dar fin a la labor.

Respondió Alonso Ortíz- - Eso, Señor, no haré yo, que quien mata a su señora es aleve a su señor.El rey no le respondiera, en su cámara se entró: enviara por dos maceros, los cuales él escogió. Estos fuéron a la reina, halláronla en oración; la reina como los viera cási muerta se cayó mas después que en si tornara esforzada les habló: - Ya sé a qué venís amigos, que mi alma lo sintió; aqueso que está ordenado no se puede excusar, no. 
¡Oh Castilla! ¿qué te hice? no, por cierto, traición.

¡Oh Francia, mi dulce tierra! joh mi casa de Borbón!

hoy cumplo deciseis años, a los decisiete muero yo.

El rey no me ha conocido, con las vírgenes me vo.

Doña María de Padilla, esto te perdono yo;

por quitarte de cuidado lo hace el rey mi señor.-

Los maceros le dan priesa, ella pide confesión:

perdonáralos a ellos, y puesta en su oración

danle golpes con las mazas, y ansí la triste murió.

¿Qué motivos podía tener el rey para no interesarse por una joven de esas cualidades? La imaginación popular y la propia propaganda pro-petrista elaboró la leyenda de que el hermanastro del rey, Fadrique Enríquez, uno de los caballeros que salió a esperar a Blanca, mantuvo relaciones amorosas con ella durante el viaje. Se alimentó la leyenda al saberse que $D$. Fadrique tuvo un hijo, del que se desconocía la madre, y se corrió el rumor de que la madre podría ser $\mathrm{D}^{\mathrm{a}}$ Blanca o una joven judía.

Entre la gente se dice, y no por cosa sabida, que del honrado Maestre don Fadrique de Castilla, hermano del rey don Pedro que por nombre el Cruel había, está la reina preñada; otros dicen que paría,

Otra variante del poema anterior denunciaba las relaciones de la joven reina, exponía con frescura su «culpabilidad», y la presentaba entregando a ese hijo para ocultarlo al rey, pues sabía el castigo que la esperaba si su esposo se enteraba:

lo que vuestra Alteza dice debe ser muy gran mentira.

-No lo es, dijo la reina, que yo te lo mostraría.-

Mandara sacar un niño que en su palacio tenía:

sacólo su camerera envuelto en una faldilla.

-Mirá, mirá, Alonso Pérez, el niño, ¿á quién parescía?

-Al Maestre, mi señora, Alonso Pérez decía.

-Pues daldo luego a criar, y a nadie esto se diga.-

Sálese Alonso Pérez, ya se sale de Sevilla;

muy triste queda la reina, que consuelo no tenía;

llorando de los sus ojos de la su boca decía:

-Yo, desventurada reina, más que cuantas son nascidas,

casáronme con el rey por la desventura mía.

De la noche de la boda nunca más visto lo había, y su hermano el Maestre me ha tenido compañía.

Si esto ha pasado toda la culpa era mía.

Doña Blanca fue objeto de propaganda por los dos bandos. Si la propaganda anti-petrista la retrató de forma favorable para resaltar la crueldad del rey, el bando petrista la atacó de manera feroz, y la denigró hasta "devaluarla», como le ocurrió en ocasiones a la moneda de su nombre, la blanca: 
Doña Blanca de Borbon / Mi padre me puso en Francia, No entendiendo que mi suerte / Tan en blanco me dejara.

Bien pensó mi padre el Duque / Que su Blanca acá en España

Que valiera una corona / Y ante el Rey no valgo blanca.

Como no me selló el Rey / Con el sello de su gracia

Soy moneda forastera / Que en este reino no pasa.

Don Pedro, defendido por su bando como «justiciero», fue denostado como «cruel» por el bando contrario. En su oposición, el bando anti-petrista no se limitó a utilizar la figura de su esposa legítima, sino que se valió de todo el grupo femenino en relación con el monarca. Comenzó incluso por la propia madre del rey. Con el ánimo de demostrar la ilegitimidad de Pedro I, lo que le pondría al mismo nivel que el adalid del grupo opositor, Enrique II, se puso en tela de juicio la legitimidad de su nacimiento, afirmando que no era hijo de Alfonso XI, sino fruto del adulterio de la reina con un judío llamado Pero Gil.

Sin embargo, por encima de cualquier otra mujer, la figura femenina más denostada por la propaganda anti-petrista fue la de la amante del rey, María de Padilla. Los enemigos de Pedro I se encargaron se difundir rumores que hacían de ella una criatura diabólica, que habría utilizado algún artilugio o maleficio para atraer al monarca y alejarle de $D^{a}$ Blanca ${ }^{31}$. La retrataban tan pérfida como para pedir a Pedro la ejecución de su hermanastro don Fadrique, acusado de ser el seductor de Blanca de Borbón:

Día de todos los Reyes, primera fiesta del año, todas damas y doncellas al rey piden aguinaldo, a no ser doña María, que a la puerta se ha quedado. - ¿Qué pides, doña María, qué pides por aguinaldo?

- Yo lo que pido, buen rey, que me ha de ser otorgado,

si `o pedía la cabeza del maestro de Santiago.

- Las cabezas de hombres buenos no se dan por aguinaldo.

- ¡Aprisa, aprisa, mis criados, y aprisa van degollarlo!Le han cortado la cabeza y a María la entregaron.

María, c’aquella rabia, a los perros la ha tirado.

Los perros, con ser perros, la llevaron al sagrado;

con las patas, sepultura, con la boca, la enterraron.

Varias versiones de este poema añaden más defectos a la amante del rey:

Hoy es día de los Reis, primera fiesta del año,

- ¿Qué haces, doña María, que no pides aguinaldo?

- L’aguinaldo que yo quiero no me será otorgado.

- Sí será, doña María, aunque `o baje de mi estado.

-Yo quería la cabeza del maestro de Santiago.

31. En la Crónica de Pedro / se califica de hechicera a María de Padilla, que hechizó, sin duda, al rey. 
- ¡Qué mal hicieste, María, que ese tal es mi hermano.

Siete hermanos que tenía por puta los has matado!-

La propaganda en contra de Pedro y María llevaba a aceptar el adulterio de la reina Blanca y el alumbramiento del niño, del que era conocedora María de Padilla:

\footnotetext{
Mientras se cria el infante sábelo doña María aquella falsa traidora que los reinos revolvía. No estaba bien informada cuando al rey se lo escrebia:

- Yo, tu leal servidora, doña María de Padilla, que no te hice traición, ni consentir la quería, para que sepas, soy cierta de aquesto te avisaría; quién te la hace, señor, declarar no se sufría, hasta que venga a tiempo que de mí a tí se diría.
}

El final de la balada expone un juicio moral y religioso ${ }^{32}$ sobre la figura histórica de María de Padilla, y condena a su espíritu a volar eternamente, rechazada por Dios y el diablo:

Doña María de Padilla Por los aires va volando;

Por sus buenas fechorías No la quiere Dios ni el Diablo.

La elección de una mujer de esa índole como amante apoyaba la idea de un Pedro «cruel». Se establecía una correspondencia entre la figura de un rey «justiciero» o «cruel» en relación con las mujeres. El desprecio a su mujer legítima, que le impedía tener herederos legítimos, se mostraba como un rechazo al viejo orden cristiano, e incluso se dejaba entrever su querencia a los judíos. Sin embargo, las hijas ilegítimas que Pedro había tenido con María de Padilla, habían sido aceptadas por las Cortes como herederas legítimas del reino, lo que no aceptaban los Trastamaras, que pregonaban la ilegitimidad:
a grandes voces decía: -Morirás, el rey don Pedro, que mataste sin justicia los mejores de tu reino: mataste tu propio hermano el Maestre, sin consejo, y desterraste a tu madre: a Dios darás cuenta de ello. Tienes presa a doña Blanca, enojaste a Dios por ello, que si tornas a quererla darte ha Dios un heredero, y si no, por cierto sepas vendrá desman por ello: serán malas las tus hijas por tu culpa y mal gobierno, y tu hermano don Henrique te habrá de heredar el reino: morirás a puñaladas: tu casa será el infierno.
Todo esto recontado, despareció el bulto negro.

No hay dudas sobre la utilización propagandística del grupo femenino de la familia real, especialmente si se contempla la diferencia entre los reinados de Alfonso

32. A. J. CRUZ, «The Female Figure as Political Propaganda in the «Pedro el Cruel» Romancero», 78. 
XI y Pedro I. Si se tiene en cuenta que no había habido mucha diferencia entre el padre y el hijo en lo referente a su conducta familiar, la reacción de la nobleza fue muy diferente en uno y otro caso. El padre no padeció el enconamiento de la nobleza como el hijo, y de ese odio al rey salieron mal paradas las mujeres, prueba de que las mujeres víctimas del rey lo fueron especialmente de los intereses políticos de los enemigos de Pedro I, que vieron en ellas una buena fórmula para atacar al monarca.

\section{LAS MUJERES EN EL CONFLICTO ENTRE ENRIQUE IV E ISABEL DE CASTILLA}

Hubo un tercer momento en la historia de la monarquía castellano-leonesa, en el que también aparecen las mujeres en la propaganda política de bandos enfrentados. Ese momento es el de la lucha abanderada por una parte importante de la nobleza en contra de Enrique IV, monarca que estaba caminando con pasos decididos en el afianzamiento de la autoridad regia, ante la displicencia de la noble$\mathrm{za}^{33}$. En este caso, como en los anteriores, los nobles atacaron al monarca utilizando a las figuras femeninas de su entorno en campañas propagandísticas intensísimas, que tuvieron como punto de partida las problemáticas relaciones de Enrique IV con sus esposas.

A Enrique IV se le había concertado su primer matrimonio en 1436, cuando él tenía once años, y su desposada, Blanca de Navarra, doce. Tras treces años de matrimonio «espiritual», probablemente no consumado, el monarca pidió la anulación para poder casarse de nuevo, legítimamente, con Juana de Portugal ${ }^{34}$.

El matrimonio de Enrique IV y Juana de Portugal se celebró en 1455. Los cronistas informan del acontecimiento, aunque en versiones poco coincidentes:

«Luego llegada los desposorios fueron celebrados por don Alfonso de Fonseca, arzobispo de Sevilla, y pasados tres días se celebraron las bodas»35.

"Y el dia de Pascua de Conquema el rey se veló con la reina, su esposa, y velólos don Alfonso, electo confirmado de la iglesia de Mondoñedo... y luego el rey y la reina cabalgaron y con ellos todos los grandes que en la Corte estaban y fueron a oir misa solemne a la iglesia mayor, la cual dijo el arzobispo embajador de Francia» ${ }^{36}$.

33. Isabel del VAL VALDIVIESO, «Los bandos nobiliarios en el reinado de Enrique IV», Hispania, 35 (1958), pp. 249-293.

${ }^{34}$. Una bula del papa, fechada en Roma en diciembre de 1453, le permite casarse con la princesa Juana de Portugal, pues está clara la anulación eclesiástica de su matrimonio anterior. Real Academia de la Historia, Valdeflores tomo 7 sin foliar.

35. Crónica del Rey D. Enrique el IV de este nombre, por su capellán y cronista Diego Enríquez del Castillo.

36. Memorial de diversas hazañas. Crónica de Enrique IV, ordenada por Mosén Diego de Valera, ed. J. de M. CARRIAZO, Madrid, 1941, p. 19. 
"Celebró el arzobispo de Tours la solemnidad de las bodas aunque sin la dispensa apostólica; agüero que añadía otras nulidades futuras a la anteriormente declarada, así como la experiencia del primer matrimonio amenazaba con mayores peligros a los que iban a unirse en infecundo consorcio ${ }^{37}$.

Ninguno de los cronistas ponía en duda la legitimidad del matrimonio, aunque Alonso de Palencia, gran defensor posteriormente de la reina Isabel la católica, apuntaba que se había celebrado sin la dispensa apostólica.

Pasaron cinco años hasta que la reina Juana quedó embarazada, aunque antes ya había tenido un aborto. Habían corrido las noticias de la inexistencia de relaciones entre los esposos, por la impotencia del monarca, algo que no se demostró entonces, ni se ha podido demostrar posteriormente ${ }^{38}$. En los medios populares se decía que la reina había sido "fecundada antes de desflorada», es decir, habría sido inseminada artificialmente. Así lo explicó Jerónimo Münzer, un viajero extranjero por España, que describió la inseminación realizada mediante una caña de oro construida por médicos, que la habían introducido en la vagina de la reina, para inyectar por ella el semen del rey ${ }^{39}$.

El nacimiento de una niña, la princesa Juana, fue bendecido en medios eclesiásticos, como demuestra el sermón que predicó Rodrigo Sánchez de Arévalo en el Vaticano, en el que no para en elogios a la reina Juana:

«Pero a la verdad qué podremos decir sobre su excelentísima esposa, la más preclara de la reinas?... Es nuestra muy ínclita Reina hermosa de rostro, más hermosa de costumbres, proviene de estirpe regia y brilla fúlgida junto a su marido. Humilde en su conversación, prudentísima en sus consejos, plena de fe, de oración asidua, férvida en su oración, ávida del culto divino. Diremos, por tanto, con justicia con el Sabio: Muchas mujeres hicieron proezas, pero ella con el adorno de virtud y la honestidad las supera a todas, por eso las reinas le alabaron, y con razón el rey le amó, la adornó y la introdujo en su cámara, esto es, la colocó en la intimidad de sus secretos. Mereció quedar fecundada y dar a luz la que con asidua diligencia estaba adornada de virtudes» ${ }^{40}$.

Los elogios a la reina se encuentran también en medios literarios, como demuestran estos versos de Gómez Manrique:

Soys de viçios enemiga, secaçes de joventud, de bondad y de virtud,

\footnotetext{
37. Alonso de Palencia, Crónica de Enrique IV. Madrid, Atlas, 1973-1975

38. G. MARAÑÓN, Ensayo biológico sobre Enrique IV de Castilla y su tiempo, Madrid, Espasa-Calpe, 1953.

39. «Fecerunt medici cannam auream, quam Regina in vulvam recepit, an per ipsam semen inicere posset», J. MÜNZER, Viaje por España y Portugal 1494-1495, Madrid, 1951, p. 108.

${ }_{40}$ Tarsicio de AZCONA, Juana de Castilla, mal llamada la Beltraneja. Vida de la hija de Enrique IV de Castilla y su exilio en Portugal (1462-1530), Madrid, La Esfera de los Libros, 2007.
} 
así me dé Dios salud, ninguna fue tan amiga como vos, en quien es tanta perfección de gentileza, que no sólo mi rudeza, mas los más sabios espanta. ${ }^{41}$

Estos elogios distaban mucho de la imagen de la reina difundida luego por las Coplas del Provincial, trovas populares donde Juana de Portugal no salía bien parada:
A tí, diosa del deleite, gran señora de vasallos, dícenme que tienes callos en el rostro, del afeite, y que vuestra señoría tiene tres dientes postizos, que sabe mucho de hechizos y estudia nigromancía. ${ }^{42}$

Esta propaganda contraria a la reina concordaba con la de algunos cronistas. Valera, interesado en mantener y difundir la idea de la impotencia del monarca, escribía que el día del matrimonio de Enrique IV con Juana de Portugal, «a la noche el rey y la reina durmieron en una cama y la reina quedó tan entera como venía». Alonso de Palencia criticaba duramente a las jóvenes portuguesas que vinieron con la reina, e indirectamente a ella, tachándolas de indecentes por «más inclinadas a la seducción de lo que a doncellas conviene», y lucir trajes que descubrían «desde los pezones de los pechos hasta el ombligo».

El cambio de actitud hacia la reina no tenía otro origen que el enconamiento de las desavenencias entre nobleza y rey, a quien querían desacreditar. Una de las formas de desautorizar al monarca era cargar las tintas sobre su mujer, creando una imagen de pecaminosa, coqueta y seductora. El siguiente paso fue decir que el rey no era el padre de la hija de la reina. Alonso de Palencia apunta al posible padre:

«prefería entre todos sus capitanes a Don Beltrán de la Cueva, y le profesaba afición tan desmedida que... quiso... fuese el principal señor en su casa y aun, por su deseo, también en el lecho conyugal, por más que la Reina, resistiéndose durante largo tiempo al insolente mandato, enviaba mensajeros a su hermano el

41. Gómez Manrique, Cancionero castellano del siglo XV, ed. de Raymond FOULCHÉ-DELBOSCH, Madrid, Bailly Baillière, 1915, vol. II, pp. 48b- 50a.

42. Coplas del Provincial, J. RODRÍGUEZ PUÉRTOLAS, Poesía crítica y satírica del siglo XV, Madrid, 1981 , p. 254. 
rey de Portugal con quejas proporcionadas a la naturaleza de las infamias en que no consentía» ${ }^{43}$.

Este cronista delata la posible homosexualidad del rey, y la utilización de su favorito como semental para la reina Juana. Fueran ciertas o no estas sospechas, lo que parece probable es que la reina mantuvo su virtud, y durante años Juana fue una mujer fiel, con todo su interés puesto en dar un heredero a la corona de Castilla ${ }^{44}$.

Cuando nació la princesa Juana no parece que hubiera dudas de que era hija del rey. El propio monarca había celebrado el embarazo de la reina, y al nacer hizo lo acostumbrado: dirigir una carta a las ciudades del reino para anunciarles la buena nueva y rogarles que hicieran las «albricias» o fiestas por tan fausto motivo. El bautizo fue una solemne ceremonia eclesiástica con intervención de varios obispos, y dos padrinos y dos madrinas (una de ellas su joven tía Isabel, la hermanastra de su padre). Meses después del nacimiento de Juana, los procuradores en cortes reunidos en Madrid juraron a la princesa como heredera del reino. Después también lo harían los nobles.

Si Juana era reconocida como heredera en 1462, a finales de 1464 su padre se rendía a las peticiones de la nobleza, y aceptaba como heredero a su hermanastro el joven príncipe Alfonso, resolviendo el problema mediante matrimonio: «don alfonso min hermano casará con la prinçesa doña Juana e que pública nin secretamente non serán nin procurarán en que case con otra nin ella con otro». ${ }^{45}$

La situación cambió por completo, primero al fallecer el príncipe Alfonso en 1468, y luego al casarse Isabel de Castilla con Fernando de Aragón sin el consentimiento del monarca castellano. Aquí empieza el tiempo de mayor utilización de las mujeres en la propaganda en contra de Enrique IV y de su hija Juana, y a favor de la princesa Isabel.

La que había sido madrina de Juana al nacer, su tía Isabel, se convertiría pronto en su mayor enemiga. En un documento de Autodefensa, redactado por su can-

43. Alonso de Palencia. Crónica de Enrique IV, I, 5, 7. La idea de que Beltrán de la Cueva era el favorito del rey, venía de que se le consideraba la pareja homosexual del rey cuando éste era mozo. De ahí que la fama alcanzara a la literatura popular y Las Coplas del Provincial incluyeran los siguientes versos referidos a Beltrán de la Cueva:

y es pública voz y fama / que odiste personas tres:

a tu amo y a tu ama / y a la hija del marqués;

odes al rey y a la reyna, / odes las tres Badajoces,

y todo el mundo se espanta / como no odes a la infanta

El amo era el rey Enrique IV, con quien se rumoreaba que mantenía relaciones homosexuales; el ama era la reina Juana de Portugal; y la hija del marqués era su propia esposa, hija del segundo marqués de Santillana. Las tres «badajoces» debían de ser mujeres de la familia Badajoz, y la infanta que se libraba del apetito sexual de Beltrán de la Cueva era la princesa Isabel, luego reina Isabel la Católica.

${ }^{44}$. Alonso de Palencia. Crónica de Enrique IV, I, 1, 2. «la casta consorte rechazase en una lucha sin testigos tamaña maldad»

${ }^{45}$ AHN Sección Nobleza, Frías 15-6. Citado por T. de AZCONA, Juana de Castilla, p. 52. 
cillería, la princesa Isabel defendía su nombramiento en Guisando, al tiempo que difamaba a Juana, a quien llamaba y siempre llamaría «la hija de la Reina»46. Un documento de contraataque sacó la cancillería de Juana «la beltraneja» tras la muerte de su padre. Alli llamaba a Isabel «reina de Sicilia», como consorte de Fernando, rey de Sicilia ${ }^{47}$.

Pocas son las alusiones al tema en los romances. Solo uno refleja la pérdida de derechos de doña Juana según lo había ordenado su padre Enrique IV, lo que ayudaba a afianzar a nivel popular la legitimidad de la reina Isabel:

Muy grandes gentes se ayuntan / en los Toros de Guisando.

Señores y caballeros / y también muchos prelados

Vienen con doña Isabel / para verse con su hermano,

Porque por su sucesora / el rey la había señalado.

Todos hablaron al Rey, / todos le besan la mano:

El Rey con semblante alegre /a todos ha perdonado;

$\cdots$

Absolvió del juramento / que el Rey les había tomado,

Al tiempo que a doña Juana / por princesa habían jurado

Por contemplación del Rey / que los había forzado;

Y porque del juramento / todos habían reclamado,

Ya del juramento absueltos, / el Rey les ha asi hablado:

- Perlados y caballeros, / los que aquí estáis ayuntados,

Yo os mando que en mi presencia / jureis delante el Legado

Por sucesora en mis reinos / desque yo sea finado,

A Doña Isabel mi hermana / y que la beseis la mano,

Porque en todas las ciudades / así lo tengo mandado. ${ }^{48}$

La utilización de las figuras de Juana e Isabel no se limita a aspectos políticos, sino que incluye también tintes sociales. Al divulgar el mal ejemplo de una reina se denunciaba un modelo de mala mujer, capaz de cometer adulterio, aunque el objetivo fundamental fuera atacar al rey. El modelo femenino que encarnaba Isabel era justamente el contrario, el de joven honesta, recatada, muy católica, espejo para las mujeres de su tiempo. Ella sería buena mujer y buena reina ${ }^{49}$.

La oposición al rey se realizó tomando como instrumentos a dos de las mujeres de la familia: su hermana Isabel y su hija Juana la Beltraneja. Aunque parece evidente que Juana era hija de Enrique IV, hubo mucho interés en difundir una patraña, de lo contrario Isabel ni hubiera sido la reina de Castilla. La propagación de la idea de que el monarca era impotente entraría en la categoría de la difusión de

46. Memorias de don Enrique IV de Castilla..., pp. 630-639. T. de AZCONA, Juana de Castilla, p. 73.

47. J. FERNÁNDEZ DOMINGUEZ, La guerra civil a la muerte de Enrique IV. Zamora-Toro-Castronuño, Zamora, 1929, p. 25. Un original en Archivo Municipal de Zamora. leg. XIX n.19. Citado por T. de AZCONA, Juana de Castilla, p. 74.

48. Agustín DURÁN, Romancero General. Colección de romances castellanos anteriores al siglo XVIII, BAE, vol. 16, Madrid, edit. Atlas, 1945, pp. 65-66.

49. Ese modelo de buena mujer y buena reina se difunde por Fr. Martín de Córdoba en el libro dedicado a la joven princesa Isabel, el Jardín de nobles doncellas. 
ideas inciertas, pero imposibles de borrar. El «calumnia que algo queda» estaría en la base del asunto; fue tan eficaz la propaganda que aún hoy, aunque los estudiosos del tema proclamen la paternidad de Enrique $\mathrm{IV}^{50}$, resulta difícil no dudar de la posible impotencia del monarca. Buena obra, pues, de la propaganda aquel tiempo.

\section{PARA CONCLUIR: FIGURAS FEMENINAS EN LA PROPAGANDA POLÍTICA}

Años después de la muerte de Isabel, cuando Fernando regresó desde Aragón a Castilla en 1507, aparece una mujer en la bien engrasada máquina de propaganda política de aquel reinado. Era María de Santo Domingo, la terciaria dominica citada al principio, claro ejemplo de utilización de una mujer como instrumento de propaganda política. Se ve claramente en el caso del Cardenal Cisneros, pero más descaradamente en el de Fernando el Católico. «las palabras y acciones de María les ayudaban a consolidar su poder, rubricaban sus políticas y apoyaban su prestigio y sentido de identidad " ${ }^{51}$. María de Santo Domingo estaba respecto a estos hombres en una relación de patrono-cliente, bastante típica entre la política y la religión.

La beata de Piedrahita podía servir para apoyar la figura carismática del rey, reafirmando la línea pretendida con anterioridad de presentar a Fernando como figura semi-divina, en una especie de «mesianismo oficial». Sus profecías parecían cumplirse y ayudaba así al rey a conseguir y afirmar su prestigio en las líneas políticas que desarrollaba. Las profecías de la beata caían dentro de categorías ideológicas ampliamente circuladas o difundidas. Algunos de los proyectos de Fernando eran grabados con el sello de la ordenación divina, al ser difundidos, aunque de manera inconexa, por la beata. Eso les daba credibilidad, necesaria en una corte en mala situación como la de los años posteriores a la muerte de Isabel. Fernando tenía sus propagandistas, y utilizaba a la monja como parte de esa propaganda. Lo mismo que Fernando hizo el cardenal Cisneros, que la utilizó en la reforma conventual y religiosa que llevaba a cabo.

Fernando utilizó a esta mujer para conseguir sus objetivos al final de su reinado, como al principio se había manipulado a otras mujeres. María de Santo Domingo difería formalmente de las anteriores, no respondía al modelo medieval típico de los tres momentos históricos expuestos. Las mujeres de esos tres tiempos estudiados tenían en común los siguientes rasgos:

$1^{\circ}$. Fueron mujeres que, voluntaria o forzadamente, se vieron envueltas en conflictos provocados por concepciones de poder divergentes, tomaron partido por uno de los bandos, y se involucraron en una de las facciones en litigio.

50. Gregorio MARAÑÓN, Ensayo biológico sobre Enrique IV de Castilla y su tiempo, y T. de AZCONA, Juana de Castilla.

51. J. BILINKOFF, «A Spanish Prophetess and Her Patrons: The Case of María de Santo Domingo», Sixteenth Century Journal, 23, 1, 1992, 21. 
$2^{\circ}$. Las diferencias en las concepciones de poder provocaban los conflictos familiares, especialmente cuando grupos nobiliarios se enfrentaban a la forma de gobierno del monarca, y apoyaban a alguno de los miembros de la familia.

$3^{\circ}$. En los tres casos, las mujeres se vieron envueltas en conflictos sucesorios entre hermanos, que terminaron en guerras o graves enfrentamientos. El fenómeno de la propaganda está indisolublemente unido a la historia de la guerra, de ahí que se genere más intensidad de propaganda a través de romances o medios similares como consecuencia de enfrentamientos políticos y bélicos entre miembros de la familia real, que quieren apoderarse del poder.

$4^{\circ}$. Se las presenta como mujeres que no pueden servir de modelo a las demás ${ }^{52}$. En todas ellas se explota algún escándalo sexual, se entremezcla algún tema de sexualidad inusual, desviada o pecaminosa, es decir, una conducta sexual inaceptable: de doña Urraca se divulga que tiene una relación incestuosa con su hermano Alfonso ${ }^{53}$, de la reina Blanca de Borbón que tiene una relación adúltera e incestuosa con su cuñado Fadrique, y de la reina Juana que comete adulterio con Beltrán de la Cueva. El adulterio, fácilmente tomado como alegoría política, parece ser cosa únicamente de mujeres. Este aspecto de la propaganda confirmaría la idea de que los romances «recrean y delimitan ciertas formas de conducta de género" ${ }^{54}$.

$5^{\circ}$. Se las utiliza en romances y baladas con doble finalidad propagandística: la política de apoyo o rechazo al rey, y la de divulgación de unos modelos de conducta femenina.

El ciclo de baladas de Pedro el Cruel, en el que se presentan las figuras de la esposa legítima del monarca con sus amantes, no solo divide los papeles de hombre y mujer en el binomio activo/pasivo, sino que explícitamente compara y condena la mujer activa sobre la victimización femenina ${ }^{55}$. Sin embargo, este aspecto no queda de manifiesto tan claramente en los romances sobre doña Urraca, pues no se presenta una condena de la mujer activa que fue la infanta.

A pesar de las similitudes entre los tres casos estudiados, es difícil aplicar un patrón unitario. Ello se manifiesta en primer lugar por el medio de difusión de la propaganda, que difiere algo en los tres casos. Los dos primeros momentos fueron transmitidos fundamentalmente por los romances, el tercero por las crónicas.

\footnotetext{
52. Doña Urraca «no es mujer modélica», D. CATALÁN, La épica española. Nueva documentación y nueva evaluación. Madrid, Fundación Ramón Menéndez Pidal, 2000, p. 44.

53. Se hace eco de esta historia una fuente árabe, el Bayan de Ibn Idari (R. MENÉNDEZ PIDAL y E. LÉVI-PROVENÇAL, «Alfonso VI y su hermana la infanta Urraca», Al-Andalus, 13, 1948, 157-166), y una fuente cristiana, fray Juan Gil de Zamora, De Praeconiis Hispaniae, y De Praeconiis Civitatis Numantiae, editada la primera en manuscritos de la Biblioteca Nacional (1508), y la segunda editada por Fidel FITA en el Boletín de la Academia de la Historia en el año 1884. Citan estas fuentes A. GAMBRA, Alfonso VI: cancillería, curia e imperio, I. Estudio,León, 1997, y D. CATALÁN, La épica española. Nueva documentación, p. 149-51.

54. A. J. CRUZ, «The Female Figure as Political Propaganda in the «Pedro el Cruel» Romancero», p. 69.

${ }^{55}$. A. J. CRUZ, «The Female Figure as Political Propaganda in the «Pedro el Cruel» Romancero», p. 69.
} 
El problema de Juana la beltraneja difería de los otros como para no difundirlo de igual manera. Por una parte no hubo necesidad de divulgarlo en momentos posteriores, como ocurrió con los casos de doña Urraca y de Pedro I; pero además con su transmisión solo se podía sembrar más dudas acerca de la ilegitimidad de los gobernantes, de hecho hasta la muerte de Juana la beltraneja, que falleció el mismo año que murió Juana la loca, Carlos I tuvo cierta desconfianza de la excelente señora doña Juana por temor a que pudiera pretender el trono, y los monarcas portugueses aprovecharon esa situación en sus relaciones diplomáticas con Castilla ${ }^{56}$.

Los romances, dado su potencial literario y capacidad para muy variadas temáticas, recibieron múltiples funciones y tipos de historias. Sirvieron de noticieros, recogiendo acontecimientos coetáneos. El papel de los romances en la expansión de ideas fue fundamental tanto para expandir modelos de conducta femenina, así como para realizar una propaganda a favor o en contra de los varones de la casa real. Lo consiguen muy bien los romances por llegar a grupos sociales muy amplios, más que otras formas literarias como las crónicas o los cancioneros.

Aunque el mundo femenino medieval habría que definirlo en buena medida por su invisibilidad, las mujeres emergen en distintas facetas de la vida de aquel tiempo, y una de ellas es la de la propaganda. Las mujeres fueron, en efecto, instrumento de propaganda política y de socialización, tal como muestran los ejemplos seleccionados. Esos ejemplos responden a la tendencia medieval de utilizar un personaje con fines propagandísticos sin ningún escrúpulo de si se era fiel a la verdad o no ${ }^{57}$, al tiempo que muestran la paradoja de la utilización de las mujeres en los medios políticos, de los que los varones estaban empeñados en excluirlas.

56. Así lo defiende T. de AZCONA en Juana de Castilla.

57. P. STAFFORD, Queens, Concubines and Dowagers: The King's Wife in the Early Middle Ages (Women, Power, and Politics), Londres y Washington, Leicester University Press, 1998: «Los retratos que muestran las crónicas no pueden aceptarse sin cuestionarse. Cualquier forma posible de distorsión se encuentra en ellas: cotilleos maliciosos, propaganda política, supresión deliberada de hechos, conocimiento inadecuado, antifeminismo, simples mentiras.», p. 3. 